\title{
Posterior Transverse Plication of Tortuous Internal Carotids in Post Stroke Carotid Endarterectomy
}

\author{
Hussien Rabee*, Tamer Ghatwary, Khaled Al-Omar, Nee Beng Teo and Ragai Makar \\ Department of Vascular Surgery, UK
}

*Corresponding author: Hussien M Rabee, Department of Vascular Surgery, Countess of Chester Hospital, NHS Foundation trust, South Merseyside Arterial Centre, Vascular Surgery, CH2 1UL, Chester, UK.

Received Date: October 22, 2018

Published Date: November 09, 2018

\section{Abstract}

Background: Post-operative ICA stenosis secondary to an arterial kinking had been documented in patients who had a tortuous ICA. Posterior transverse plication (PTP) is one of the surgical manoeuvres used during CEA for a significantly tortuous ICA to prevent an arterial kinking stenosis after the carotid surgery.

Aim of the study: To highlight the role of PTP in the management of a tortuous ICA and preventing the stenosis from an ICA kinking during CEA.

Methods: We reviewed retrospectively six consecutive patients with symptomatic carotid disease who underwent the PTP during CEA in the presence of a significantly tortuous ICA.

Results: One female and 5 males with a median age of 67 years (range: 65 to 78) years underwent the surgery. None developed any neurological event and post-operative scan did not show any ICA thrombosis or stenosis from an ICA kinking after a median follow-up of 6 months (range: 5 to 17).

Conclusion: We believe that PTA of ICA during CEA is an easy, simple procedure and safe surgical technique with potential benefits in the presence of a significantly tortuous ICA.

Keywords: Carotid; Plication; Tortuous; Kink; Stenosis; Endarterectomy

\section{Introduction}

Carotid endarterectomy (CEA) is one of the most commonly performed procedures in vascular surgery [1]. The efficacy of CEA is well validated with a significant stroke risk reduction in patients with symptomatic internal carotid artery (ICA) stenosis [2,3]. Strong evidences showed that combined CEA and best medical therapy are superior when compared with medical therapy alone in the prevention of stroke recurrence [2-4]. However, there are potential risks and complications associated with CEA. Postoperative ICA stenosis secondary to arterial kinking had been documented in patients who had a tortuous ICA $[5,6]$. This stenosis is thought to be hemodynamically significant if the Peak Systolic Velocity (PSV) $>120 \mathrm{~cm} / \mathrm{s}$ and raises the concern of recurrent cerebrovascular events $[7,8]$.

Posterior transverse plication (PTP) is one of the surgical manoeuvres used during CEA for a significantly tortuous ICA to prevent an arterial kinking stenosis after the carotid surgery [9]. It was firstly described by Ruckley et al. \& Riles et al. [9-11] in 1993 and 1995 respectively. Other known techniques include shortening of ICA, eversion CEA, or the application of biological glue (such as gelatin or fibrin) to fix and maintain the position of the tortuous ICA during CEA [12-17]. The risk of developing thrombosis at the site of PTP remains unknown, and little is known about the efficacy and effectiveness of the above techniques to prevent an arterial kinking stenosis during CEA in the presence of significantly tortuous ICA.

The aim of this study is to present our experience in performing PTP in patients with a tortuous ICA during CEA for their symptomatic carotid disease.

\section{Methods}

We reviewed retrospectively over 12 years' time, six consecutive patients with symptomatic carotid disease who underwent PTP 
during CEA in the presence of a significantly tortuous ICA. They were managed in two vascular centres: 1) The Security Forces Hospital, Riyadh, Saudi Arabia, and 2) The Countess of Chester Hospital, Chester, UK. The cases were considered symptomatic if the patient had a documented stroke, transient ischaemia attack (TIA) or amaurosis fugax within the previous six months. Every patient underwent two diagnostic modalities (Carotid Duplex scan and Carotid CT Angiography) and was demonstrated to have a significant ICA disease ( $>60 \%$ stenosis) as well as a significant tortuous ipsilateral ICA. The tortuosity was considered when there was an unusual redundant ICA which required excision at least a $5 \mathrm{~mm}$ segment to straighten the vessel after CEA.

PTP (Figures 1-4) was performed during CEA by transversely folding and suturing the redundant posterior wall externally with continuous 5/0 Proline. The selected length of the folded portion depended on the adequate segment needed to shorten the ICA and straighten the tortuous segment. Patients' verbal consents were obtained for presentation and publication (Figures 1-4).

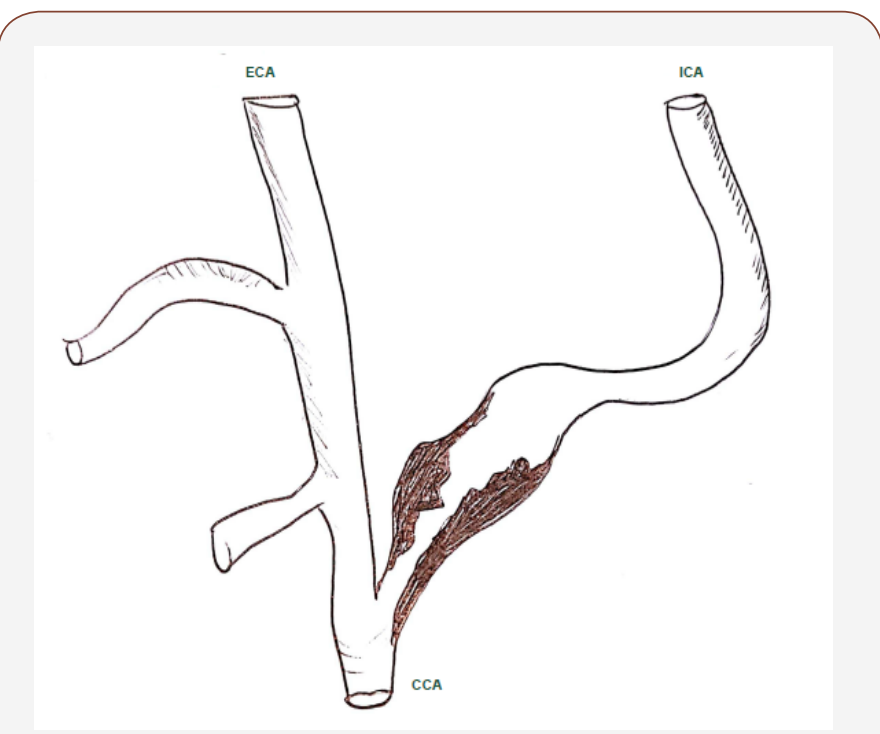

Figure 1: Tortuous ICA with significant stenosis.

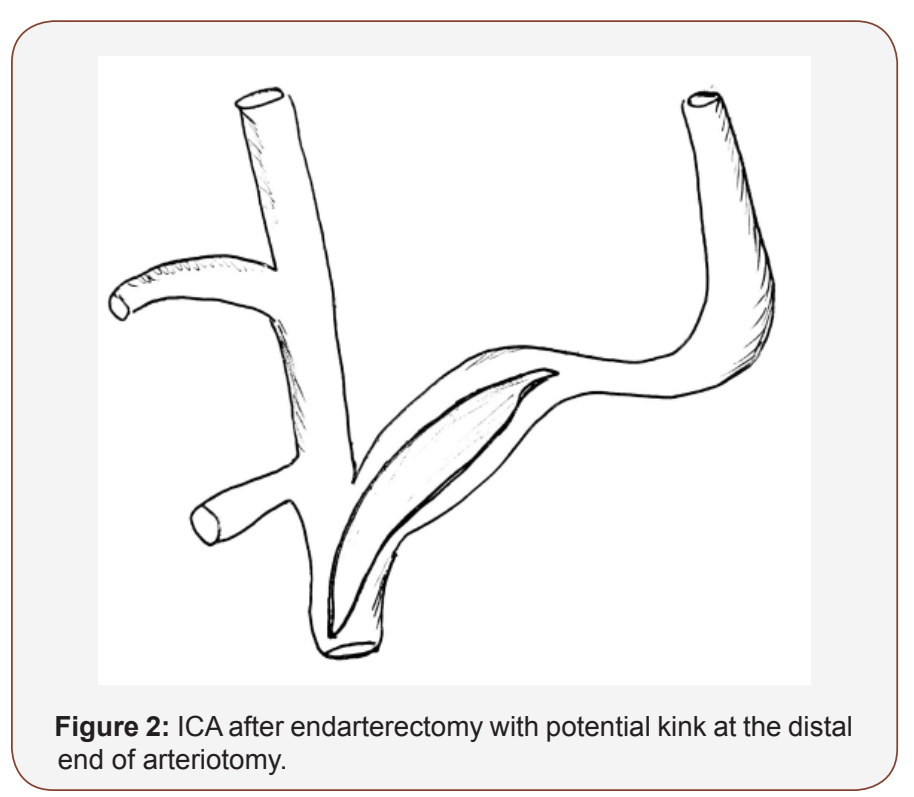

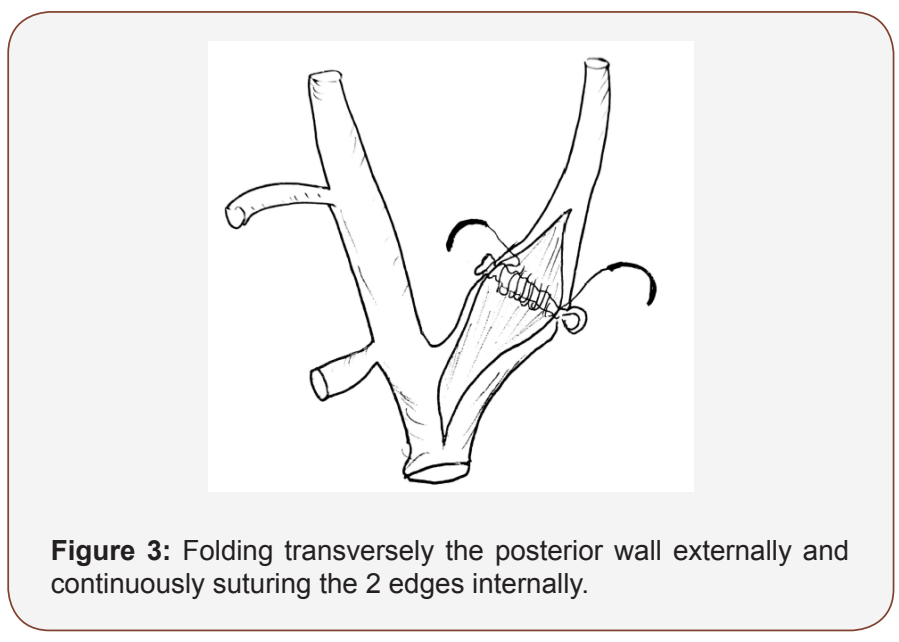

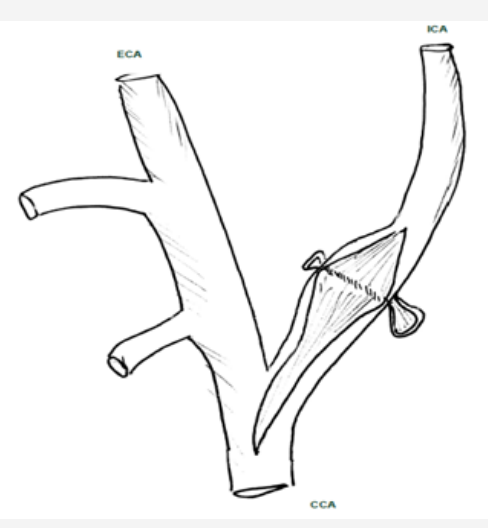

Figure 4: Final outcome of PTP with shortening and straightening of the ICA.

\section{Result}

Five of the six patients were males. Patient age ranged from 65 to 78 years (mean: 69; median: 67). Five patients had a past medical history of hypertension, 3 patients had coronary artery disease, one patient was diabetic, 3 patients had hyperlipidaemia, 2 patients had peripheral vascular disease and 4 patients were smokers (Table 1). One patient presented with an amaurosis fugax, 4 patients with TIAs, and one patient had a minor stroke with good recovery (Graph 1). Two patients had 60-69\% ipsilateral ICA stenosis, 3 had 70\%-89\% ICA stenosis and one had $>90 \%$ ICA stenosis (Table 2). Two patients underwent CEA with a planned PTP based on the pre-operative scans demonstrating a significantly tortuous ICA. 4 patients had an unplanned PTP as part of an intraoperative decision in the presence of a significantly redundant internal carotid artery (Table 3).

Table 1: Patients risk factors.

\begin{tabular}{|c|c|}
\hline Risk Factors & Number of Patients \\
\hline Male & 5 \\
\hline Hypertension & 5 \\
\hline Diabetes Mellitus & 1 \\
\hline Smoking & 4 \\
\hline Hyperlipidaemia & 3 \\
\hline Ischemic Heart Disease & 3 \\
\hline Peripheral Vascular Disease & 2 \\
\hline
\end{tabular}


Table 2: Degree of ipsilateral internal carotid stenosis before surgery.

\begin{tabular}{|c|c|c|c|}
\hline $\begin{array}{c}\text { Degree of } \\
\text { stenosis }\end{array}$ & $\begin{array}{c}\text { Number of } \\
\text { patients }\end{array}$ & $\begin{array}{c}\text { Carotid Du- } \\
\text { plex Scan }\end{array}$ & $\begin{array}{c}\text { Carotid CT Angiog- } \\
\text { raphy }\end{array}$ \\
\hline $60-69 \%$ & 2 & + & + \\
\hline $70-89 \%$ & 3 & + & + \\
\hline$>90 \%$ & 1 & + & + \\
\hline
\end{tabular}

Table 3: Planned and unplanned posterior transverse plication (PTP) during carotid surgery.

\begin{tabular}{|c|c|}
\hline Planning for PTP & Number of Patients \\
\hline Pre-operative & 2 \\
\hline Intra-operative & 4 \\
\hline
\end{tabular}

Graph 1: Presentations before CEA

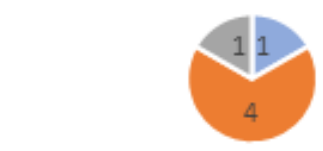

- Amaurosisfugax . TIA " Minor Stroke

Graph 1: Clinical presentations before carotid surgery

Every patient underwent a standard CEA with a patch angioplasty under general anaesthesia. None developed an intraor post-operative neurological complication. Every patient was reviewed in a follow up vascular clinic along with a carotid duplex scan in the clinic. The patients' median follows up was 6 months with a range of 5 to 17 months. Every patient was alive and free from any recurrent cerebrovascular event. None developed ipsilateral
ICA thrombosis or significant restenosis.

\section{Discussion}

Redundant and significantly tortuous ICA is associated with a potential risk of compromised cerebral perfusion during the carotid surgery for patients with a symptomatic ICA stenosis [18]. Tortuosity is defined as a kinking with a single or multiple angulation(s) in the presence of redundant vessel. ICA tortuosity may affect the cerebral haemodynamic blood flow significantly $[19,20]$. Studies found ICA tortuosity is present in up to $16 \%$ of the general population and 5\% among patients undergoing carotid surgery [19]. Although the debate regarding to treat or not treat ICA kinking, the risks of affecting cerebral blood flow during and after CEA are well known to vascular surgeon. It is very interesting to experimentally report a $40 \%$ drop of blood flow with arterial angulation of 600 and more than $60 \%$ drop if the angle decreases to $30^{\circ}$ [21]. Angulation of a transverse portion of the tortuous ICA at the cranial end of the carotid shunt may obstruct the cerebral perfusion through the shunt. The risk can be minimised by careful selection, placement as well as frequent intra-operative assessment of the adequacy of the carotid shunt including direct connection with arterial line or transcranial doppler monitoring. Carotid endarterectomy results in the thinning and weakening of the tortuous internal carotid arterial wall with the potential risk of arterial kinking and compromised cerebral perfusion [5,20]. Arterial kinking and stenosis with intra-operative stroke with or without ICA thrombosis had been documented in several studies [22-25].

Arterial kinking and stenosis can be addressed by an arterial shortening manoeuvre. The value of the arterial shortening had been documented by studies with a range of follow-up from 3 to 145 months (Table 4) [10,15,19,26-29].

Table 4: Publications of posterior transverse plication of internal carotid artery (NA: Data was not described in the study).

\begin{tabular}{|c|c|c|c|c|}
\hline Publications & Number of Procedures ICA & Mean Age & Follow Up Months Mean (Range) & Follow Up Months Median (Range) \\
\hline Poorthuis et al. [19] & 29 & 73 & $34.3(3-145)$ & NA \\
\hline Falkensammer et al. [26] & 3 & 75 & $10.7(1-58)$ & NA \\
\hline Ascher et al. [27] & 82 & 77 & $13.8($ NA) & NA (1-44) \\
\hline Makhdoomi et al. [10] & 84 & 69 & NA & NA \\
\hline Archie [15] & 147 & NA & $67(8-129)$ & NA \\
\hline Sottiurai et al. [28] & 49 & NA & NA & $6(6-6)$ \\
\hline Lauterjung et al. [29] & 12 & & \\
\hline
\end{tabular}

Like our series, no peri-operative neurological events or carotid artery thrombosis were reported. We believe that with the lack of comparative randomised study, long-term follow-up for ICA restenosis rate will be of little value as it is hard to determine the cause of ICA restenosis (whether it is part of the disease progression or the aftermath of PTP). In a randomized controlled study, 144 cases in 134 patients underwent CEA without plication of ICA tortuosity, had follow up duplex scan at median of 2 months (range 1-55 months) and showed a stenosis of $<50 \%$ in six $(7 \%)$ and a stenosis of $50-75 \%$ in six (7\%) and complete occlusion in one patient [10]. Such observation highlights the benefit of ICA PTP.

The rational of an arterial shortening is usually based on the surgeon assessment of severity of redundant or tortuous ICA during the carotid surgery to minimise the mentioned potential complications. Different shortening procedures had been described in the literature, namely the excision of the redundant ICA during an eversion CEA [16,17] or the excision of extra-length ICA [12]. 
Other studies described different ways to maintain the shape and position of the redundant or tortuous ICA by, re-implantation at common carotid artery [20], looping around sternomastoid or digastric muscle with or without fixation in position using gelatin or fibrin $[14,19,30]$.

Eversion CEA is a technically demanding procedure which needs specific training with a steep learning curve. This manoeuvre also precludes the opportunity to maintain peri-operative cerebral perfusion via the carotid shunting. Excision of an ICA segment followed by the re-implantation to a common carotid artery requires two complete anastomoses with the potential risks of bleeding, twisting or thrombosis. Fixing the thin walled redundant or tortuous ICA around muscular neighboured structure needs more evidence regarding the efficacy and clinical outcome. We believe this series is retrospective and more prospective large number of cases will support our outcome.

\section{Conclusion}

We believe that technically PTP is less demanding and safer. In our series, we found the PTP is a simple and easy technique. The manoeuvre does not compromise the carotid shunting during CEA; and the redundant or tortuous thin walled ICA post CEA can be both shortened and straightened with no additional thrombogenic suture line. PTP is reversible and sutures can be taken away if the plication found be tight or still inadequate. Cases requiring PTP are uncommon and are far in between. A larger series of patients with longer follow-up in controlled trials is essential to determine the long-term efficacy of the PTP procedure.

\section{Acknowledgement}

None.

\section{Conflict of Interest}

\section{No conflict of interest.}

\section{References}

1. Lokuge K, de Waard DD, Halliday A, Gray A, Bulbulia R, et al. (2018) Meta-analysis of the procedural risks of carotid endarterectomy and carotid artery stenting over time. Br J Surg 105(1): 26-36.

2. [No authors listed] (1987) North American Symptomatic Carotid Endarterectomy Trial. Methods, patient characteristics, and progress. Stroke 18(6): 987-989.

3. Trial Collaborators, Barnett HJM, Taylor DW, Haynes RB, Sackett DL, et al. (1991) Beneficial effect of carotid endarterectomy in symptomatic patients with high-grade carotid stenosis. North American Symptomatic Carotid Endarterectomy. N Engl J Med 325(7): 445-53.

4. Morris DR, Ayabe K, Inoue T, Sakai N, Bulbulia R, et al. (2017) EvidenceBased Carotid Interventions for Stroke Prevention: State-of-the-art Review. J Atheroscler Thromb 24(4): 373-387.

5. Yuan JY, Durward QJ, Pary JK, Vasgaard JE, Coggins PK (2014) Use of intraoperative duplex ultrasonography for identification and patch repair of kinking stenosis after carotid endarterectomy: Asingle-surgeon retrospective experience. World Neurosurg 81(2): 334-343.

6. Horio Y, Takemoto K, Sakamoto S, Inoue T (2018) Endovascular reconstruction for a kinked internal carotid artery after carotid endarterectomy. Surgical Neurology International 9: 135.
7. Vannix J, Nadijafi AS, Stalker CG (1977) Surgical treatment of kinked internal carotid artery. Clinical significance and surgical management. Am J Surg 134: 82-89.

8. Koskas F, Bahnini A, Walden R, Kieffer E (1993) Stenotic coiling and kinking of the internal carotid artery. Ann Vasc Surg 7(6): 530-540.

9. Naylor AR, Ruckley CV (1996) Complications after carotid surgery. In: Campbell B (edn), Complications in Arterial Surgery, a Practical Approach to Management, Butterworth Heinemann, London, pp. 73-88.

10. Makhdoomi KR, McBride M, Brittenden J, Bradbury AW, Ruckley CV (1993) A Prospective Study of Internal Carotid Artery Plication During Carotid Endarterectomy: Early Clinical and Duplex Outcome. Eur J Vasc Endovasc Surg 18(5): 391-394.

11. Riles TS, Jacobowitz GR (1995) Etiology and management of perioperative stroke after carotid endarterectomy. In: Callow AD, Ernst CB (edn). Vascular Surgery Theory and Practice. Appleton and Lange, USA, pp. 1247-1253.

12. Poindexter JM, Patel KR, Clauss RH (1987) Management of kinked extracranial cerebral arteries. J Vasc Surg 6(2): 127-133.

13. Collins PS, Orecchia P, Gomaz E (1991) A technique for correction of carotid kink and coil following endarterectomy. Ann Vasc Surg 5(2): 116-120.

14. Kubota H, Sanada Y, Tanikawa R, Kato A (2016) The use of fibrin and gelatin fixation to repair a kinked internal carotid artery in carotid endarterectomy. Surg NeurolInt 7(Suppl 15): S434-436.

15. Archie JP (1993) Carotid endarterectomy with reconstruction technique tailored to operative findings. J Vasc Surg 17: 141-151.

16. Raithel D, Kasprzak P (1993) The eversion endarterectomy: a new technique. In: Greenhalgh RM, Hollier HL (edn). Surgery for Stroke London: WB Saunders, London, pp. 183-191.

17. Koskas F, Kieffer E, Bahnini A, Ruotolo C, Racurel G (1995) Carotid eversion endarterectomy: short- and long-term results. Ann Vasc Surg 9(1): 9-15.

18. Metz H, Murray-Leslie RM, Banniste, RG, Bull JW, Marshall J (1961) Kinking of the internal carotid artery. Lancet 1(7174): 424-426.

19. Poorthuis MH, Brand EC, Toorop RJ, Moll FL, De Borst G (2014) Posterior transverse plication of the internal carotid artery to correct for kinking. J Vas Surg 59(4): 968-977.

20. Ballotta E, Thiene G, Baracchini C, Ermani M, Militello C, et al. (2005) Surgical vs medical treatment for isolated internal carotid artery elongation with coiling or kinking in symptomatic patients: a prospective randomized clinical study. J Vasc Surg 42(5): 838-846.

21. Koskas F, Bahnini A, Walden R, Kieffer E (1993) Stenotic coiling and kinking of the internal carotid artery. Ann Vasc Surg 7(6): 30-40.

22. Derrick JR, Estess M, Williams D (1965) Circulatory dynamics in Kinking of carotid artery. Surgery 58: 381-383.

23. Mukherjee D, Inahara T (1985) Management of the tortuous internal carotid artery. Am J Surg 149(5): 651-655.

24. Schechter DS (1979) Dolichocarotid syndrome. Cerebral ischemia related to cervical carotid artery redundancy with kinking. Parts I and II. NY State J Med 79: 1391-1397 (1542-1549).

25. Kubota H, Sanada Y, Tanikawa R, Kato A (2016) The use of fibrin and gelatin fixation to repair a kinked internal carotid artery in carotid endarterectomy. Surg Neurol Int 7(Suppl 15): S434-436.

26. Falkensammer J, Hakaim AG, Oldenburg WA, Berland TB (2007) Common carotid artery imbrication as an adjunct to carotid endarterectomy to prevent postoperative carotid kinking. Am Surg 73(3): 276-278.

27. Ascher E, Hingorani A, Gunduz, Y, Mazzariol F, Yorkovich W (2001) Posterior transverse plication technique for treatment of redundant internal carotid artery during endarterectomy. Cardiovasc Surg 9(1): 16-19.

28. Sottiurai VS, Gonzales J, Omlie W, Cooper M, Lyon R, et al. (1998) Plication for correction of excessive carotid artery kinking, unacceptable torn end 
point, and perforation from plaque erosion: techniques and results. Vasc Surg 32(4): 307-314.

29. Lauterjung KL, Pratschke E, Stiegler H, Becker HM (1980) A new operative technique for kinking stenoses of the internal carotid artery. Thorac Cardiovasc Surg 28: 352-353.
30. Szekely G, Csecsei GI (2001) Anteposition of the internal carotid artery for surgical treatment of kinking. Surg Neurol 56(2): 124-126. 